\title{
Plasma Xanthine Oxidase Activity in Patients With Adult Respiratory Distress Syndrome
}

\author{
Cyril M. Grum, Richard A. Ragsdale, Loren H. Ketai, and Richard H. Simon
}

\begin{abstract}
Oxygen metabolites have been implicated in the pathogenesis of various types of acute tissue injury. One biologic source of oxygen metabolites is the reaction catalyzed by the enzyme xanthine oxidase. Because we previously demonstrated that the substrates for xanthine oxidase (hypoxanthine and xanthine) are elevated in the plasma of critically ill patients, we questioned whether the enzyme itself might also be present. We therefore measured hypoxanthine concentration and xanthine oxidase activity in the plasma of 15 patients with ARDS and in 13 non-ARDS critically ill patients. Plasma xan-
\end{abstract}

$\mathbf{T}$ HE MECHANISMS of injury in the adult respiratory distress syndrome (ARDS) have been the subject of considerable interest. One category of mediators implicated in the pathogenesis of acute lung injury are the toxic oxygen metabolites. ${ }^{16}$ In addition to evidence from animal models of ARDS, there is now evidence that oxygen metabolites are present in human ARDS, ${ }^{7}$ and can alter lung constituents. ${ }^{8}$ Oxygen metabolites can be generated from many sources and are thought to play a role in some forms of ischemic injury. ${ }^{9,10}$ An additional source of oxygen metabolites is stimulated neutrophils, which have been implicated as an agent of alveolar injury in ARDS. ${ }^{4-6,11,12}$ Whether additional sources of oxygen metabolites participate in human ARDS is not certain.

The enzyme xanthine oxidase produces the oxygen metabolites superoxide anion and hydrogen peroxide when it oxidizes hypoxanthine or xanthine to uric acid. ${ }^{9,10,13,14}$ These oxygen metabolites can then form a variety of additional

From the Pulmonary and Critical Care Medicine Division, Department of Internal Medicine, University of Michigan Medical Center, Ann Arbor.

Supported in part by grants from the National Institutes of Health (5-MOIRR42, 25S2; HL31963) and from the American Heart Association with funds contributed in part by the American Heart Association of Michigan (84-1058).

Address reprint requests to Cyril M. Grum, MD, Division of Pulmonary and Critical Care Medicine, University of Michigan Medical Center, 3916 Taubman Center, 1500 E Medical Center Dr, Ann Arbor, MI 48109-0360.

(C) 1987 by Grune \& Stratton, Inc.

$0883-944 I / 87 / 020 I-0003 \$ 05.00 / 0$ thine oxidase activity in our ARDS group $(1,514 \pm 975 \mathrm{mlU} / \mathrm{L}$, mean $\pm \mathrm{SE})$ was higher than that seen in the non-ARDS group $(17 \pm 4 \mathrm{mIU} / \mathrm{L}$, $P \leq .05)$. Plasma hypoxanthine was elevated in both groups, and there was no difference between the ARDS and non-ARDS groups $(22.0 \pm 9.2 \mu \mathrm{mol} / \mathrm{L}$ and $11.8 \pm 4.3 \mu \mathrm{mol} / \mathrm{L}$, respectively). The presence of both circulating xanthine oxidase and its substrate demonstrates the potential for intravascular oxygen metabolite production. These toxic products may then cause tissue injury in ARDS.

(c) 1987 by Grune \& Stratton, Inc.

toxic compounds. ${ }^{10,15}$ When xanthine oxidase and xanthine are instilled intratracheally into rat lungs or perfused through the vasculature of isolated rabbit lungs, oxygen metabolites are generated and acute high permeability lung edema occurs. ${ }^{16-19}$ In the cat intestine and dog heart, ischemia activates endogenous xanthine oxidase, which generates toxic oxygen metabolites and causes acute tissue injury. ${ }^{9,14,20} \mathrm{We}$ have previously demonstrated increased concentrations of hypoxanthine and xanthine in the plasma of critically ill patients including those with ARDS. ${ }^{21}$ Although xanthine oxidase is normally undetectable in human plasma, ${ }^{22,23}$ we questioned whether it may be present in ARDS. Because of the ability of xanthine oxidase to generate toxic oxygen metabolites and the suspected role of these metabolites in ARDS, we measured the activity of endogenous xanthine oxidase in the plasma of ARDS patients.

\section{MATERIALS AND METHODS}

\section{Patients}

We studied 15 patients with ARDS. Our diagnostic criteria for ARDS were modified from Fowler et al. ${ }^{24}$ Acute respiratory failure requiring mechanical ventilation, diffuse bilateral alveolar infiltrates on chest roentgenogram, requirement of an $\mathrm{F}_{1} \mathrm{O}_{2}$ of greater than 0.6 to maintain a $\mathrm{P}_{\mathrm{a}} \mathrm{O}_{2}$ above 60 torr, and the absence of left ventricular failure (pulmonary artery wedge pressure $\leq 18$ ). Non-ARDS patients who had acute illnesses requiring admission to an intensive care unit were studied concurrently. All non-ARDS patients had no evidence of diffuse lung injury but required supplementary oxygen and an arterial catheter for management. No patient was receiving allopurinol at the time of study. This study was approved by the Human Subject Review Committee of the University of Michigan. 


\section{Sample Collection}

Ten milliliters of arterial blood was collected into prechilled tubes containing heparin, erythro-9-(2 hydroxy-3 nonyl) adenine hydrochloride, and dipyridamole. ${ }^{21}$ The latter two chemicals were necessary to prevent purine degradation and transcellular fluxes of adenosine. The sample was immediately centrifuged at $1,500 \mathrm{~g}, 4^{\circ} \mathrm{C}$ for ten minutes, and the plasma separated and frozen at $-70^{\circ} \mathrm{C}$ until analysis. The ARDS patients were studied as soon as possible after they met diagnostic criteria and always within 24 hours of developing the syndrome.

\section{Xanthine Oxidase Activity}

We measured xanthine oxidase activity by monitoring the rate of conversion of ${ }^{14} \mathrm{C}$-hypoxanthine to ${ }^{14} \mathrm{C}$-xanthine and ${ }^{14} \mathrm{C}$-uric acid, modifying the technique of Sinclair and Fox. ${ }^{25}$ Ten microliters of plasma was added to $30 \mu \mathrm{L}$ of $0.05 \mathrm{~mol} / \mathrm{L}$ potassium phosphate buffer, $\mathrm{pH} 8.5$, and $10 \mu \mathrm{L}$ of ${ }^{14} \mathrm{C}$ hypoxanthine $(56 \mathrm{mCi} / \mathrm{mmole}, \mathrm{ICN})$. The final concentration of ${ }^{14} \mathrm{C}$-hypoxanthine was $95 \mu \mathrm{mol} / \mathrm{L}$. The sample was then incubated in a shaking water bath at $37^{\circ} \mathrm{C}$ for 60 minutes. The reaction was stopped by the addition of $10 \mu \mathrm{L}$ of $1.7 \mathrm{~mol} / \mathrm{L}$ perchloric acid. After a ten-minute centrifugation at $1,500 \mathrm{~g}, 5 \mu \mathrm{L}$ of supernatant was spotted on $3 \mathrm{~mm}$ Whatman chromatography paper. Forty microliters of an internal marker consisting of a mixture of $10 \mathrm{mmol} / \mathrm{L}$ hypoxanthine, xanthine, and uric acid in $0.05 \mathrm{~mol} / \mathrm{L}$ potassium phosphate buffer, pH 8.5 , was also spotted on the chromatography paper. The compounds were separated using high voltage electrophoresis (Gilson) in $50 \mathrm{mmol} / \mathrm{L}$ sodium borate buffer, $\mathrm{pH} 8.9$, at $3.5 \mathrm{kV}$ for 35 minutes. After drying, the compounds were identified under ultraviolet light and the radioactivity determined by scintillation counter. The activity of xanthine oxidase is expressed as $\mathrm{mIU} / \mathrm{L}$ plasma. One international unit of xanthine oxidase will metabolize one micromole of hypoxanthine per minute.

\section{Plasma Hypoxanthine}

Plasma hypoxanthine concentration was determined by high pressure liquid chromatography using an acetylnitrile gradient as previously described. ${ }^{21}$ In brief, plasma was deproteinized by filtration and then divided into two aliquots, one of which was treated with specific enzymes to convert all intermediate products of adenosine triphosphate (ATP) degradation to uric acid. Loss of the peak eluting at the same time as authentic hypoxanthine in the enzyme treated sample confirmed its identity as hypoxanthine. By comparing the peak areas to known calibration standards, the plasma hypoxanthine concentration was obtained.

\section{Statistical Analysis}

Group data was expressed as mean \pm SE. Data from ARDS and non-ARDS groups were compared by the Wilcoxon nonpaired rank sum test. Probability values less than .05 were considered significant.

\section{RESULTS}

The characteristics of the ARDS and nonARDS patients are shown in Table 1. There were
Table 1. Characteristics of Patient Populations

\begin{tabular}{|c|c|c|}
\hline & ARDS & Non-ARDS \\
\hline$n$ & 15 & 13 \\
\hline Age $(y r) \pm S E$ & $46 \pm 3$ & $56 \pm 5$ \\
\hline $\mathrm{F}_{1} \mathrm{O}_{2} \pm \mathrm{SE}$ & $0.82 \pm 0.05$ & $0.54 \pm 0.06$ \\
\hline \multicolumn{3}{|l|}{ Associated di- } \\
\hline \multirow[t]{10}{*}{ agnosis* } & Sepsis (3) & Sepsis (4) \\
\hline & Pneumonia (3) & Pneumonia (3) \\
\hline & & Postoperative compli- \\
\hline & Trauma (4) & cations (4) \\
\hline & & Acute cerebrovascula \\
\hline & Aspiration (3) & event (2) \\
\hline & Hypertransfusion (2) & Hypertransfusion (2) \\
\hline & & Cardiogenic shock (2) \\
\hline & & Chronic abstructive \\
\hline & $\begin{array}{l}\text { Hypovolemic shock } \\
\text { (1) }\end{array}$ & $\begin{array}{l}\text { pulmonary disease } \\
\text { (3) }\end{array}$ \\
\hline
\end{tabular}

* Some patients had more than one associated diagnosis.

five females in each group. There was evidence of pulmonary dysfunction in both groups as demonstrated by the need for supplemental oxygen. There was no difference between the groups in cardiac output, systolic blood pressure, or serum creatinine. The ARDS group had a lower arterial $\mathrm{pH}(7.35 \pm 0.02)$ than the non-ARDS group $(7.42 \pm .02, P \leq .05)$.

Plasma xanthine oxidase activity of the two groups is presented in Fig 1. The mean xanthine oxidase activity in the ARDS group $(1,514 \pm 975 \mathrm{mIU} / \mathrm{L})$ was higher than that seen in the non-ARDS group $(17 \pm 4 \mathrm{mIU} / \mathrm{L}$, $P \leq .05)$. Eight of fifteen patients with ARDS had plasma xanthine oxidase activities higher than any of the non-ARDS group, (range, 94 to $14,000 \mathrm{mIU} / \mathrm{L}$ ). The three patients with the highest levels of circulating xanthine oxidase had elevated liver function tests (serum glutamic oxaloacetic transaminase, alkaline phosphatase, bilirubin) suggesting that severe ischemic liver damage might have been a source of the xanthine oxidase. Excluding these three patients, levels of abnormal liver function tests did not correlate with serum xanthine oxidase activity in either group. Of the two patients in the non-ARDS group with the highest levels of xanthine oxidase activity ( 39 and $61 \mathrm{mIU} / \mathrm{L}$ ), one had elevated liver function tests and the other did not.

Plasma levels of hypoxanthine are shown in Fig 2. The plasma level of hypoxanthine in the ARDS group $(22.0 \pm 9.2 \mu \mathrm{mol} / \mathrm{L})$ was not different from that seen in our non-ARDS group $(11.8 \pm 4.3 \mu \mathrm{mol} / \mathrm{L})$. However, the levels in both 


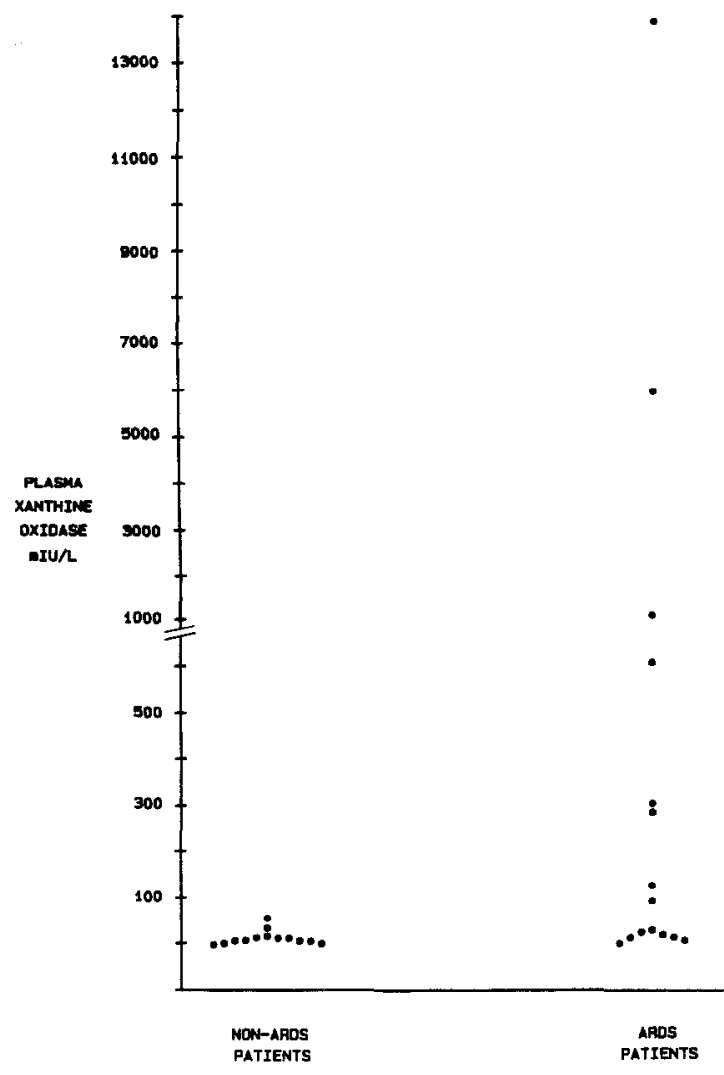

Fig. 1. Plasma xanthine oxidase activity in the ARDS patient group ( $n=15$ ) and the non-ARDS patient group $(n=13)$. The mean \pm SE activity in the ARDS group $(1,514+975 \mathrm{mlU} / \mathrm{L})$ was significantly higher than in the non-ARDS group $(17 \pm 4 \mathrm{mlL} / \mathrm{L}, P \leq .05)$.

groups were much higher than those of the 14 healthy volunteers $(1.1 \pm 0.1 \mu \mathrm{mol} / \mathrm{L})$ that we have previously reported. ${ }^{26}$ There was no correlation between the plasma level of hypoxanthine and the activity of xanthine oxidase in either group. No correlation was seen between xanthine oxidase levels and measurements of lung dysfunction within the ARDS group, but the sizes of the subgroups were small.

\section{DISCUSSION}

The mechanism of lung injury in ARDS is probably multifactorial. Animal studies have suggested that toxic oxygen metabolites may be one important mechanism of acute tissue damage. ${ }^{1-6}$ Oxygen metabolites may be generated from many sources including the metabolism of hypoxanthine by the enzyme xanthine oxidase. ${ }^{9,10}$ Exogenous administration of this enzyme and substrate either intratracheally or intravascularly has caused acute permeability

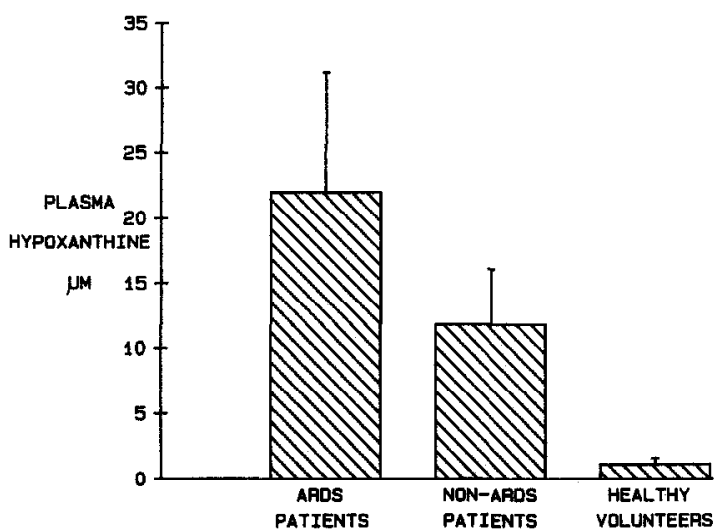

Fig 2. Plasma hypoxanthine concentrations in ARDS patients and non-ARDS patients. Mean \pm SE values are presented. Although there was no difference between the ARDS $(22.0 \pm 9.2 \mu \mathrm{mol} / \mathrm{L})$ and non-ARDS groups $(11.8+4.3 \mu \mathrm{mol} / \mathrm{L})$, both of these values are higher than that found in a group of 14 normal volunteers $(1.1 \pm 0.1$ $\mu \mathrm{mol} / \mathrm{L}$ ), which we have published previously. ${ }^{26}$

lung injury in animal models. ${ }^{16-19}$ Furthermore, there is evidence suggesting that endogenous enzyme and substrate may participate in acute tissue injury in other organ systems such as the dog and rat myocardium and cat intestine., ${ }^{9,1420}$ Circulating xanthine oxidase is normally undetectable in human serum. ${ }^{22,23}$ Levels of plasma xanthine oxidase found in this study are of comparable magnitude to those which have caused lung damage in experimental models. ${ }^{17,27}$ The present study demonstrates that some patients with ARDS have elevation of both hypoxanthine and xanthine oxidase activity. We therefore have documented the presence of an enzyme that can catalyze the production of toxic oxygen metabolites together with its substrate in patients with ARDS. Of note, in a study of infant respiratory distress syndrome, allopurinol (an inhibitor of xanthine oxidase) caused decreased infant mortality when compared to placebo. ${ }^{28}$ Although infant respiratory distress syndrome differs from ARDS in its initiating factors, after it is established it shares many characteristics with ARDS. ${ }^{29}$

ARDS is a systemic disorder with evidence of diffuse capillary damage.$^{30}$ Plasma xanthine oxidase might cause predominant lung injury if the liver is the site of its release since the alveolar capillaries are the first capillary bed exposed to its activity. Alternatively, the high oxygen concentration of the alveolar environment may predispose to injury by providing higher concentra- 
tions of the other substrate for xanthine oxidase, ie, oxygen. Saugstad has reported the occurrence of lung injury in neonatal rats (which have endogenous xanthine oxidase activity in their lungs) when he ventilated animals with $100 \%$ oxygen and perfused them with hypoxanthine. ${ }^{16}$ Injury did not occur when room air ventilation and glucose infusion were used.

The presence of multiorgan failure in many patients with ARDS suggests the presence of a circulating toxic agent. We speculate that circulating hypoxanthine and xanthine oxidase may be one of the contributors to the diffuse tissue injury seen in human ARDS. The source of circulating xanthine oxidase in our patients is unclear. In humans, two organs known to be rich in xanthine oxidase are the liver and small intestine. $^{22}$ This fact, together with our finding that the highest levels of xanthine oxidase activity were in paticnts with severe liver injury, suggests a hepatic source of the circulating enzyme in some patients. Xanthine oxidase has been reported to be present in the lung of some animal species, and may be released from the lung into the systemic circulation in the dog. ${ }^{23}$ Whether xanthine oxidase is present in human lung or is released into the circulation from the lung has not been tested. Ischemia has been shown to be a potent activator of xanthine oxidase. ${ }^{9}$ We suspect that the lower $\mathrm{pH}$ in our ARDS group was most likely due to lactic acid production by ischemic/ hypoxic tissues. This then may be another source of circulating xanthine oxidase.

We suggest that the elevated hypoxanthine levels in these patients is most likely due to tissue hypoperfusion and ATP breakdown. These levels are comparable to that previously described in critically ill patients. ${ }^{21}$ Recent work by Ketai et al has suggested that the kidney, diaphragm, and liver tissue beds are the highest sources of hypoxanthine release. ${ }^{31}$ The elevated concentration of hypoxanthine in our patients implies that hypo- xanthine release exceeds both uptake and metabolism.

We could not detect elevations of circulating xanthine oxidase in all our patients with ARDS. This may be due to the likelihood that there are multiple causes of ARDS. ${ }^{32}$ It is possible that xanthine oxidase release is part of the pathologic process of some but not all conditions associated with ARDS. Because xanthine oxidase in humans is concentrated in liver and small intestine, we speculate that a risk factor for increased plasma levels of xanthine oxidase may be patients with ischemic insults to these organs. Our finding of increased liver dysfunction and the lower systemic $\mathrm{pH}$ in patients with elevated xanthine oxidase supports this speculation. Other factors causing elevated plasma xanthine oxidase remain to be elucidated. Alternatively, circulating xanthine oxidase may have been initially present but subsequently bound or cleared by antibodies to xanthine oxidase. The presence of relatively high levels of antixanthine oxidase antibodies in the serum of normal human volunteers has been documented. ${ }^{33}$ The role of these antibodies in disease states and their possible protective effects, however, have not been delineated.

In summary, we have shown high levels of circulating xanthine oxidase activity in some patients with ARDS but not in non-ARDS critically ill patients. This activity, together with elevated circulating substrate, provides the opportunity for the generation of toxic oxygen metabolites in human ARDS. Whether toxic oxygen metabolites are, in fact, generated by this mechanism and whether inhibition of xanthine oxidase will prove beneficial in this setting, remains to be determined.

\section{ACKNOWLEDGMENT}

The authors wish to thank the nursing staff of the Critical Care Medicine Unit for their assistance in sample collection, and Robyn Byers for her secretarial assistance.

\section{REFERENCES}

1. Shasby DM, Shasby SS, Peach MJ: Granulocytes and phorbol myristate acetate increase permeability to albumin of cultured endothelial monolayers and isolated perfused lungs. Role of oxygen radicals and granulocyte adherence Am Rev Respir Dis 127:72-76, 1983

2. Perkowski SZ, Havill AM, Flynn JT, et al: Role of intrapulmonary release of eicosanoids and superoxide anion as mediators of pulmonary dysfunction and endothelial injury in sheep with intermittent complement activation. Circ Res 53:574-583, 1983

3. Sacks T, Moldow CF, Craddock PR, et al: Oxygen radicals mediate endothelial cell damage by complementstimulated granulocytes. An in vitro model of immune vascular damage. J Clin Invest 61:1161-1167, 1978

4. Till GO, Johnson KJ, Kunkel R, et al: Intravascular activation of complement and acute lung injury. Dependency 
on neutrophils and toxic oxygen metabolites. J Clin Invest 69:1126-1135, 1982

5. Ward PA, Till GO, Kunkel R, et al: Evidence for role of hydroxyl radical in complement and neutrophil dependent tissue injury. J Clin Invest 72:789-801, 1983

6. Fantone JC, Ward PA: Role of oxygen-derived free radicals and metabolites in leucocyte-dependent inflammatory reactions. Am J Pathol 107:397-418, 1982

7. Baldwin SR, Simon RH, Grum CM, et al: Oxidant activity in the expired breath of patients with the adult respiratory distress syndrome. Lancet 1:11-14, 1986

8. Cochrane CG, Spragg R, Revak SK: Pathogenesis of the adult respiratory distress syndrome: Evidence of oxidant activity in bronchoalvenlar lavage fluid. I Clin Invest 71:754761,1983

9. McCord JM: Oxygen-derived free radicals in postischemic tissue injury. N Engl J Med 312:159-163, 1985

10. Clark IA, Cowden WB, Hunt NH: Free radicalinduced patholngy. Med Res Rev 5:297-332, 1985

11. Shasby DM, Vanbenthuysen KM, Tate RM, et al: Granulocytes mediate acute edematous lung injury in rabbits and in isolated rabbit lungs perfused with phorbol myristate acetate. Role of oxygen radicals. Am Rev Respir Dis 125:443-447, 1982

12. Tate RM, Repine JE: Neutrophils and the adult respiratory distress syndrome. Am Rev Respir Dis 128:552559,1983

13. McCord JM, Roy RS: The pathophysiology of superoxide: Roles in inflammation and ischemia. Can J Physiol Pharmacol 60:1346-1352, 1982

14. Parks DA, Granger DN: Ischemia-induced vascular changes: Role of xanthine oxidase and hydroxyl radicals. Am J Physiol 245:G285-G289, 1983

15. McCord JM: The superoxide free radical: Its biochemistry and pathophysiology. Surgery 94:412-414, 1983

16. Saugstad OD: Pathogenetic aspects of respiratory distress syndrome in adults and newborns. Experimental and clinical data. Eur Surg Res 16:113-119, 1984

17. Tate RM, Vanbenthuysen KM, Shasby DM, et al: Oxygen-radical-mediated permeability edema and vasoconstriction in isolated perfused rabbit lungs. Am Rev Respir Dis 126:802-806, 1982

18. Ley K, Arfors KE: Changes in macromolecular permeability by intravascular generation of oxygen-derived free radicals. Microvasc Res 24:25-33, 1982

19. Johnson KJ, Fantone JC III, Kaplan J, et al: In vivo damage of rat lungs by oxygen metabolites. $\mathbf{J}$ Clin Invest 67:983-993, 1981

20. Chambers DE, Parks DA, Patterson G, et al: Xanthine oxidase as a source of free radical damage in myocardial ischemia. J Mol Cell Cardiol 17:145-152, 1985

21. Grum CM, Simon RH, Dantzker DR, et al: Evidence for ATP degradation in critically ill patients. Chest 88:763767,1985

22. Holmes EW, Wyngaarden JB: Hereditary xanthinuria, in Stanbury JB, Wyngaarden JB, Fredrickson DS, et al: The Metabolic Basis of Inherited Disease (ed 5). New York, McGraw-Hill, 1982, pp 1192-1201

23. Al-Khalidi UAS, Chaglassian TH: The species distribution of xanthine oxidase. Biochem .J 97:318-320, 1965

24. Fowler AA, Hamman RF, Good JT, et al: Adult respiratory distress syndrome: Risk with common predispositions. Ann Intern Med 98:593-597, 1983

25. Sinclair DS, Fox IH: The pharmacology of hypouricemic effect of benzbromarone. J Rheumatol 2:437-445, 1975

26. Ketai L, Kreit J, Simon R, et al: Relation of plasma hypoxanthine to anaerobic threshold. Clin Res 33:467A, 1985

27. Tate RM, Morris HG, Schroeder WR, et al: Oxygen metabolites stimulate thromboxane production and vasoconstriction in isolated saline-perfused rabbit lungs. J Clin Invest 74:608-613, 1984

28. Boda D, Nemeth I, Hencz P, et al: Effect of allopurinol treatment in premature infants with idiopathic respiratory distress syndrome. Dev Pharmacol Ther 7:357-367, 1984

29. Stalcup SA, Mellins RB: Acute respiratory distress in the newborn infant, in Fishman AP (ed): Pulmonary Diseases and Disorders, New York, McGraw-Hill, 1980, pp 16531666

30. Kariman K, Burns SR: Regulation of tissue oxygen extraction is disturbed in adult respiratory distress syndrome. Am Rev Respir Dis 132:109-114, 1985

31. Ketai L, Hussein F, Rosati M, et al: Tissue release of ATP degradation products during shock. Chest 89:455S, 1986

32. Rinaldo JE, Rugers RM: Adult respiratory distress syndrome. N Engl J Med 315:578-580, 1986

33. Bruder G, Jarasch E-D, Heid HW: High concentrations of antibodies to xanthine oxidase in human and animal sera. Molecular characterization. J Clin Invest 74:783-794, 1984 